\title{
Treatment satisfaction and quality of support in outpatient substitution treatment: opiate users' experiences and perspectives
}

\author{
Wouter Vanderplasschen ${ }^{1}$, Jan Naert ${ }^{1}$, Freya Vander Laenen ${ }^{2}$, and Jessica De Maeyer ${ }^{3}$ \\ ${ }^{1}$ Department of Special Education and ${ }^{2}$ Institute for International Research on Criminal Policy (IRCP) Ghent University, Ghent, Belgium, and ${ }^{3}$ Faculty \\ of Education, Health and Social Work, Centre of Expertise on Quality of Life (E-QUAL), University College Ghent, Ghent, Belgium
}

\begin{abstract}
Aims: Patient-reported outcomes have become an important source of information to guide service provision. Although opiate substitution treatment (OST) is an evidence-based and widely available intervention for opiate dependent individuals, evaluation studies have primarily focused on objective outcome indicators rather than on clients' perspectives and personal experiences. This study aims to assess opiate users' satisfaction with various aspects of substitution treatment and their subjective experiences and expectations regarding the provision of psychosocial support. Methods: The study sample consisted of 77 opiatedependent individuals who had been involved in OST for at least three months in some cities in Belgium. Qualitative interviews were used to explore clients' subjective experiences, in addition to some quantitative measures. Findings: About half of the respondents recently received some form of psychosocial support and they were generally satisfied about these services. However, the number of persons who wanted psychosocial support clearly outnumbered those actually receiving these services. Respondents stressed the importance of building trusting relationships with OST staff. Also, the need for more flexible and individualised support was emphasised. Conclusions: Compared with other stakeholders' perspectives or traditional outcome indicators, service users' subjective experiences shed an alternative light on the impact of opiate dependence and OST on individuals' daily lives. This information should be incorporated in individual treatment planning and when designing and evaluating OST services.
\end{abstract}

\section{Keywords}

Methadone, opiate addiction, quality of care, recovery, substitution treatment

History

Received 23 May 2014

Revised 18 August 2014

Accepted 26 September 2014

Published online 18 November 2014

\section{Introduction}

Patient-reported outcomes (e.g. treatment satisfaction, Quality of Life $(\mathrm{QoL}))$ have become an important source of information to guide service provision in various health care domains (Valderas \& Alonso, 2008; Wiklund, 2004). The increasing emphasis on empowerment and shared decision making has resulted in growing attention for clients' perspectives to enhance the quality of health care and to address clients' needs and expectations adequately. Also, the limitations of cure-oriented interventions for chronic disorders, including substance use disorders, have urged for a continuing care perspective and a shift from cure to care which involves (regular) monitoring of clients' views and perspectives (Wiklund, 2004).

Harm reduction is one of the central measures in the EU Drugs Strategy to reduce drug demand and risks and problems associated with substance use (European Commission, 2012). Harm reduction is characterised by a humanistic, nonjudgmental approach with respect for the autonomy of drug users and their rights for qualitative health care (Brocato \&

Correspondence: Wouter Vanderplasschen, Department of Special Education, Ghent University, H. Dunantlaan 2, B-9000 Ghent, Belgium. Tel: 32-9-331 03 13. E-mail: Wouter.Vanderplasschen@ Ugent.be
Wagner, 2003; Denning, 2001). Opiate substitution treatment (OST) is central to the harm reduction approach and is the standard treatment for heroin dependence that is widely available in most EU countries (Hedrich, Pirona, \& Wiessing, 2008). It is estimated that around $40 \%$ of all opiate dependent individuals in the EU are involved in some form of substitution treatment, mostly (66\%) methadone maintenance treatment (MMT) (EMCDDA, 2014). Buprenorphine is also frequently used as substitution medication (about 20\%), followed by less frequently prescribed substances like slowrelease morphine and diacetylmorphine (heroin).

OST is considered to be one of the most effective interventions to reduce the social, health and economic burden associated with opiate dependence (Amato et al., 2005; Kinlock, Gordon, Schwartz, Fitzgerald, \& O'Grady, 2009; Moller, Karymbaeva, Subata, \& Kiaer, 2009; Stover, 2011; Vanagas, Padaiga, \& Bagdonas, 2010). Additional psychosocial support is deemed to be essential for enhancing the effectiveness of OST (Amato et al., 2005; Vander Laenen et al., 2013; WHO, 2009). Psychosocial support refers to the many ways in which professional and non-professional members of society can support the psychological health and the social environment of the opiate user, to help improve both the quality and duration of life (WHO, 2009). Assistance can range from the simple (e.g. provision of food and shelter) to the complex (e.g. structured psychotherapy). 
Until today, most evaluation studies of opiate substitution treatment have focused on objective, socially desirable outcomes such as the reduction of illicit drug use, health risks associated with drug use and criminal behavior, with limited attention for outcomes important to opiate-dependent individuals themselves (Barnett \& Hui, 2000; De Maeyer, Vanderplasschen, \& Broekaert, 2009; Fischer, Rehm, Kim, \& Kirst, 2005; Ruefli \& Rogers, 2004). Drug users are seldom seen as important sources of information and their personal perspectives about substance abuse treatment and life in general are not widely reported in the literature (Drumm et al., 2003; Fischer, Rehm, \& Kim, 2001; Kolind, 2007; Montagne, 2002), even though such studies may present an alternative perspective on these issues (Brun \& Rapp, 2001; Vanderplasschen \& De Maeyer, 2007). Yet, information on the impact of health problems and their treatment on the daily life of individuals' suffering from chronic illnesses is often more revealing than objective outcome indicators regarding individuals' functioning or clinical recovery (Wiklund, 2004).

Despite the proven effectiveness of OST, a disproportionate number of clients drop out and leave treatment within a few months (Harris \& McElrath, 2012; Winstock, Lintzeris, \& Lea, 2011). MMT clients have voiced concerns regarding daily collections and limited methadone collection times, lengthy wait times, lack of privacy in pharmacies and the specific pharmacological qualities of methadone (Deering et al., 2011; Harris \& McElrath, 2012). Promoting retention has become a therapeutic aim in itself as it reduces relapse and mortality, but disregards the aspirations and goals of long-term MMT clients who often find themselves "stuck" in treatment (Madden, Toby, Bath, \& Winstock, 2008; Winstock et al., 2011). Besides these structural and individual barriers, also social control and stigma may challenge recovery and social inclusion of persons in MMT. Methadone provision has been associated with implicit and explicit mechanisms of social control (e.g. official registration, strict surveillance, sanctions over missed appointments), aimed at disciplining and regulating deviant behavior (Bacon \& Seddon, 2013; Harris \& McElrath, 2012). Moreover, institutional stigmatisation of methadone clients as "undeserving customers" reinforces spoiled identities (stigma disqualifies stigmatised individuals from full social acceptance) with the potential to discredit recovery instead of developing positive, non-addict self-identities (Harris \& McElrath, 2012).

\section{Aims of the study}

Despite the growing emphasis on the importance of clients' views and patient-reported outcomes in supporting persons with chronic disorders, drug users' perspectives are underrepresented in drug use treatment and research and they are seldom seen as important actors in designing services and in setting goals and evaluating treatment (Gilchrist et al., 2014). Although OST is an evidence-based and widely available intervention for opiate dependent individuals, few studies have focused on OST clients' perspectives. Available studies show opiate users' ambivalence regarding the provision and long-term benefits of MMT and its role in recovery (Harris \& McElrath, 2012; Winstock et al., 2011). Moreover, since psychosocial support is recognised as an essential element of effective OST (Amato et al., 2005, 2011; WHO, 2009), the aim of this paper is to assess clients' satisfaction with the organisation and delivery of substitution treatment, their relationship with staff involved in OST provision and their subjective experiences and expectations regarding the provision of psychosocial support. We start from opiate-dependent individuals' personal experiences and perspectives to explore the availability, intensity and desirability of psychosocial support and to measure treatment satisfaction of clients participating in substitution treatment in Belgium.

\section{Methods}

\section{Sample}

A multi-centre, cross-sectional study was set up to analyse the delivery of OST in Belgium. The study sample consisted of 77 opiate-dependent individuals who had been involved in outpatient substitution treatment for at least three months. Participants were recruited using snowball sampling and through the dissemination of flyers in pharmacies, outpatient substitution programs and GP's offices in some large Belgian cities. All respondents were over 18 years and were diagnosed as "opiate dependent" at the start of treatment. Respondents were involved in OST in Antwerp $(N=20)$, Genk $(N=15)$, Ghent $(N=12)$, Brussels $(N=10)$, Charleroi $(N=10)$ and Liège $(N=10)$. The majority of the respondents participated in methadone maintenance treatment $(93.5 \%)$, while $6.5 \%$ was maintained with buprenorphine.

In Belgium, no data are available on the number of (problem) opiate users (EMCDDA, 2014), due to the regional division of drug-related government authorities and lack of comprehensive epidemiological studies and utilisation data. The number of injecting drug users, a high risk behavior primarily associated with heroin use, is estimated to be around 3.4 cases per 1000 inhabitants aged 15 to 64. More than one third $(34.5 \%)$ of all new treatment demands in Belgium are related to opiate use. In 2012, over 17,000 persons were enrolled in substitution treatment (EMCDDA, 2014). About $90 \%$ of OST clients is prescribed methadone, while $7.5 \%$ is treated with buprenorphine. In 2008, the mean age of OST clients was 32.4 years and about a quarter (24.6\%) were female (Ledoux, 2013). In comparison with other European countries, the number of problem opiate users in Belgium appears to be in the mid-range (EMCDDA, 2014). Coverage by OST services is fairly extensive, but the proportion of primary opiate users among persons entering treatment is relatively low and diminishing.

The main characteristics of the study sample are described in Table 1. Study participants were predominantly male (79.2\%), with an average age of 41.6 years. Most respondents lived alone (37.7\%) and about half of the participants reported recent heroin use $(51.9 \%)$. The mean age of onset of substitution treatment was 28.7 years $(\mathrm{SD}=8.5)$ and, on average, respondents had been taking methadone/buprenorphine during 7.6 years $(\mathrm{SD}=4.4)$. The mean number of OST episodes was 3.4 $(\mathrm{SD}=3.4)$. Most respondents were prescribed OST by a specialised drug service $(81.8 \%)$ and were provided OST by a pharmacist (63.6\%). The majority (78.9\%) was satisfied with their current substitution dose. Eighty-five percent of the respondents had been in OST for more than one year. 


\section{Data collection}

A mixed methods design, including qualitative and quantitative research methods, was applied to counterbalance the limitations of both separate methods and to reduce eventual researcher bias (Cowman, 1993; Fountain \& Griffiths, 1999). Qualitative interviews were used to assess clients' experiences with OST staff and available psychosocial support and to identify their expectations concerning psychosocial support and OST in general. In addition, a quantitative measure of Treatment satisfaction was administered, the Verona Service Satisfaction Scale for Methadone treatment (VSSS-MT) (de los Cobos et al., 2002). Consequently, we did not only gain more insight in opiate-dependent individuals' personal perspectives about substitution treatment (Camfield, Crivello, \& Woodhead, 2009; Dunning, Williams, Abonyi, \& Crooks, 2008; Neale, Allen, \& Coombes, 2005), but also collected comparable measures regarding a number of standardised items.

All interviews $(N=77)$ took place between October 2011 and January 2012 and lasted between 25 and 120 minutes. Data were collected during face-to-face interviews in a setting chosen in consultation with the respondent (e.g. a methadone clinic, a person's house or public place). The semi-structured interviews were conducted by two female researchers, who were employed at the department of Special Education at

Table 1. Sociodemographic and drug use characteristics of the study sample $(N=77)$.

\begin{tabular}{lc}
\hline Characteristics & Sample \\
\hline Mean age (SD) & $41.58(8.56)$ \\
Male (\%) & 79.2 \\
Employment situation (\%) & \\
Paid employment & 16.9 \\
Sheltered work & 5.2 \\
Unemployed & 71.4 \\
Following training, education & 5.2 \\
Retired & 1.3 \\
Substance use in the last 30 days (\%) & \\
Alcohol & 46.4 \\
Cannabis & 53.0 \\
Benzodiazepines & 66.2 \\
Heroin & 51.9 \\
Cocaine & 29.9 \\
Substitute drug (\%) & \\
Methadone & 93.5 \\
Buprenorphine & 6.5 \\
OST prescriber (\%) & \\
General practitioner & 14.3 \\
Specialised centre & 81.8 \\
Psychiatrist & 2.6 \\
Others & 1.3 \\
OST provider (\%) & \\
Pharmacist & 63.6 \\
Specialised centre & 36.4 \\
Frequency of OST collections (\%) & \\
Daily & 39.0 \\
More than once a week & 10.0 \\
Weekly & 85.0 \\
Biweekly & \\
Monthly & 14.3 \\
Length of OST treatment (\%) & \\
3-6 months & \\
6-12 months & \\
$\geq 12$ months & \\
\hline & \\
& \\
&
\end{tabular}

Ghent University (Belgium). Written informed consent was obtained from all participants before the start of the study. Participation was entirely voluntary and confidentiality was assured. The study was reviewed and approved by the Ethical Board of the Ghent University Hospital (EC/2011/542).

Respondents received $20 €$ for participation in the study, prior to the start of the interview. Despite some ethical constraints, it has become common practice in research among hard to reach populations - in particular in community settings - to pay respondents for their participation and efforts in making time for the interview (O'Gorman \& Vander Laenen, 2010). By paying participants in advance and regardless whether they (dis)continued the interview, we tried to minimise the likelihood of social desirability towards the interviewer and to create a more equal relation between interviewer and interviewee (Allen, 2007). Yet, we cannot exclude any response bias, but all interviews took place in an open and relaxed atmosphere and respondents talked in an unrestricted way about what they liked and disliked about OST.

The quantitative part of the interview focused on client and treatment characteristics, substance use history and satisfaction with treatment. The Verona service satisfaction scale for Methadone treatment (VSSS-MT) was used as a self-report measure of satisfaction with methadone maintenance treatment. The VSSS-MT consists of 27 items and is a multidimensional measure which assesses satisfaction with treatment services in the previous three months on four domains: basic interventions, specific interventions, social worker skills and psychologist skills. The psychometric properties of the questionnaire are satisfactory (de los Cobos et al., 2002). Satisfaction with services is rated on a 5-point Likert scale, ranging from "1. Terrible" to " 5 . Excellent", which results in a satisfaction score for each domain and in an overall score for satisfaction with treatment. The range for clinical significance of VSSS-MT scores is: 1-1.99 (very dissatisfied), 2-2.99 (slightly dissatisfied), 3-3.99 (slightly satisfied), and 4-5 (very satisfied) (de los Cobos et al., 2004). For the domain specific interventions, clients are asked if they received a specific intervention (provision) and in case they did, they rated their satisfaction about this specific intervention in the same way as for the other domains. If clients did not receive a specific intervention, they are asked if they would have liked to receive this intervention (desirability) based on the following options: no; do not know; not applicable; yes (de los Cobos et al., 2002).

The qualitative phase of the study further elaborated the quantitative findings and consisted of a set of open questions focusing on participants' experiences with OST and psychosocial support (e.g. availability, frequency, type and desirability) in particular. Also, their relationship with pharmacists, medical and other staff members involved in OST was questioned.

\section{Data analysis}

Sample characteristics were assessed using descriptive statistics. Domain and overall mean treatment satisfaction scores were calculated for each participant. Since higher methadone doses $(\geq 60 \mathrm{mg})$ are more effective than lower doses for 
reducing heroin use and prolonging treatment retention (Bao et al., 2009; WHO, 2009), satisfaction scores were compared between clients with high $(\geq 60 \mathrm{mg} ; N=36)$ and low current doses of methadone $(<60 \mathrm{mg} ; n=36)$. Also, the impact of side use of heroin and the provision of psychosocial support during the last three months was assessed. To test for significant between group differences, $\chi^{2}$-tests were applied in case of categorical variables and $t$-tests for continuous variables. All statistical analyses were conducted using SPSS 19.0 (Chicago, IL). Statistical significance was set at $\alpha=0.05$.

For the analysis of the qualitative data, all interviews were audio-taped and transcribed verbatim. The transcripts were read and analysed by two of the authors. Based on the interview scheme and emerging themes, both authors developed a coding structure independently from each other. Both coding structures were merged into one coding tree including identified codes and subcodes. The coding structure was used by the last author to code all meaningful text segments in MaxQDA, a statistical software package for content analysis (Kuckartz, 1998). In case of doubt, the coding of text segments was discussed with the first author and the respective segments were coded by mutual agreement. Data were analysed in order to identify the most important themes and subthemes discussed by the participants.

\section{Results}

\section{Satisfaction with OST}

Quantitative measures indicate that the average overall satisfaction score on the VSSS-MT was $3.68(\mathrm{SD}=0.46)$. The average domain score for basic interventions was 3.73 $(\mathrm{SD}=0.60)$ and $3.40(\mathrm{SD}=0.51)$ for specific interventions, which indicate "moderate satisfaction"' based on the ranges for clinical significance. Average domain scores for psychologist $(M=4.02 ; \mathrm{SD}=0.87)$ and social worker skills $(M=4.13 ; \mathrm{SD}=0.87)$ were higher, but only a limited number of respondents had received such services. OST satisfaction was neither affected by clients' current heroin use or methadone dose, nor by the provision of psychosocial support in the last three months.

Table 2 suggests that the vast majority of respondents was moderately to highly satisfied with the OST services they received, although over $20 \%$ was not satisfied with the domains "specific interventions" and "psychologist skills".

Table 2. Categorical analysis of VSSS-MT overall and domain scores.

\begin{tabular}{lcccc}
\hline & $\begin{array}{c}\text { Very } \\
\text { dissatisfied } \\
(\%)\end{array}$ & $\begin{array}{c}\text { Slightly } \\
\text { dissatisfied } \\
(\%)\end{array}$ & $\begin{array}{c}\text { Slightly } \\
\text { satisfied } \\
(\%)\end{array}$ & $\begin{array}{c}\text { Very } \\
\text { satisfied } \\
(\%)\end{array}$ \\
\hline $\begin{array}{l}\text { VSSS-MT, overall } \\
(N=51)\end{array}$ & $/$ & 7.8 & 70.6 & 21.6 \\
$\begin{array}{l}\text { Basic interventions } \\
(N=77)\end{array}$ & 1.4 & 8.5 & 59.2 & 31.0 \\
$\begin{array}{l}\text { Specific interventions } \\
(N=67)\end{array}$ & $/$ & 28.4 & 64.2 & 7.5 \\
$\begin{array}{l}\text { Social worker skills } \\
(N=47)\end{array}$ & 6.4 & 8.5 & 38.3 & 46.8 \\
$\begin{array}{l}\text { Psychologist skills } \\
(N=26)\end{array}$ & 3.8 & 19.2 & 26.9 & 50.0 \\
\hline
\end{tabular}

The proportion of respondents that received specific services was rather low (except for individual psychotherapy and social/employment support), but a considerably larger portion would have liked to receive such support, in particular support at home, sheltered work, housing support and recreational activities (cf. Table 3).

The qualitative interviews with study participants show that the most positive effects that are associated with OST are: no longer feeling sick, regaining control over one's life (e.g. financial situation, employment/education) and being able to control or stop using heroin.

The reason I started with methadone was to become normal again, to be no longer sick, because that's really tough, when you have craving and you have no heroin available. [...] Now, I feel normal again, and I am able to function normally. (Man, 40 years old)

Being involved in determining the substitute dose is very important to most respondents, but the degree of involvement depends on the program and prescribing doctor. Limited involvement in this process may give clients the feeling that they are chained to their substitute drug for the rest of their life.

If it depends on my doctor, he will just increase my methadone dose from 50 to $80 \mathrm{mg}$ when I am not feeling well, without further questions. But I also want a say in that. If I can make it with an increase of $10 \mathrm{mg}$, there is no need to raise my dose like that. It is still my goal to get rid of that methadone. I don't want to take it for the rest of my life. (Man, 38 years old)

The most commonly cited negative aspects of OST provision are the lack of supervision and liberal prescription policy.

My previous doctor, he gave me everything I wanted. He gave me Captagon, a very strong amphetamine, and Vesparax that had the opposite effect. I took this combination [...] The next morning you wake up, you have nothing left, everything is taken away from you and you can't remember anything.(Woman, 45 years old)

Table 3. Provision and desirability of specific interventions $(N=67)$.

\begin{tabular}{lcc}
\hline & $\begin{array}{r}\text { Provision of } \\
\text { services (\%) }\end{array}$ & $\begin{array}{c}\text { Desirability of } \\
\text { services (\%) }\end{array}$ \\
\hline Family psychotherapy & 5.3 & 19.4 \\
Legal assistance & 14.3 & 21.2 \\
Group psychotherapy & 3.9 & 30.4 \\
Individual psychotherapy & 35.1 & 33.3 \\
Social and work support & 40.3 & 41.0 \\
Recreational activities outside & 15.6 & 40.0 \\
$\quad$ the centre & & \\
Housing support & 9.1 & 40.6 \\
Recreational activities at the centre & 10.4 & 42.9 \\
Sheltered work & 10.4 & 45.3 \\
Help at home & 2.6 & 49.2 \\
\hline
\end{tabular}


Limited "pressure" to change and frequent contacts with other (active) drug users are further mentioned as limitations of OST practices, affecting the atmosphere in drug services negatively.

It all happens in front of the treatment centre: dealing, selling methadone... It is very easy to relapse, because you are constantly faced with reality. (Man, 46 years old)

Also, several participants stated that specialised services primarily address clients who are in really bad shape (i.c. those still using heavily, living in marginalised conditions), at the expense of those who are doing relatively well.

They only deal with the worst cases here in the centre; I really think that is a dramatic mistake. People who are trying to cope and do well, they don't get the support they need. (Man, 35 years old)

Other negative aspects of OST that were frequently mentioned by respondents are the "dependence" on the substitute drug (e.g. daily collections, not being able to travel), side effects of substitution drugs (e.g. feeling tired, sweating heavily), wait lists and wait times to start up OST, indefinite treatment duration, stigmatisation and discrimination as a result of substitution treatment and the persistent need for other drugs (e.g. alcohol, cannabis) to replace heroin.

When asked how they saw their substitution treatment evolve in the future, almost all respondents expressed the desire to decrease their current treatment dose and, ultimately, to be no longer dependent on substitute drugs.

My goal is to stop with my methadone treatment, but slowly, because I have seen dozens, hundreds of clients who relapsed again after a few days and that's not my goal. I have been in treatment for four years now and once I stop, I don't want to start over again a couple of months later. (Man, 37 years old)

\section{Relationships with service providers}

\section{Pharmacists' role}

Most respondents received their substitute drugs through a local pharmacy and had a good relationship with their pharmacist. Pharmacists' personal commitment and the establishment of a trusting relationship is highly appreciated by OST clients.

The relationship with my pharmacist is very good. I never had problems. She is like a mum to all of us. She is really nice. It's not only: "Here are your drugs", but "How are you doing?'. Whenever I have a problem, I can always go and talk to her about it. When I lost my boyfriend nine months ago, she was very supportive. She even came to the funeral. It is not only a pharmacist, but a real mother figure. (Woman, 47 years old)

Being able to go to the pharmacy for OST provision is evaluated very positively, since it reduces the number of contacts with other (active) drug users and increases the flexibility of substitute collection (e.g. opening hours, take home doses). Also, it allows the discrete provision of medication and a more personal approach.

To give you an example, the pharmacy only opens at 8.30 a.m., but I need to take my train at 8.30 to go to my training. She gave me the permission to pick up my medication at 8.15 and I could just walk in the pharmacy. (Man, 40 years old)

Negative experiences included difficulties to find a pharmacist who was willing to provide substitution treatment or being referred to a pharmacist in another neighbourhood, resulting in limited accessibility. In some specific cases, respondents reported stories of stigmatisation and being treated disrespectfully.

She puts my methadone right at the counter in front of everyone, to say: "This is my junk, craving for his daily dose of methadone". (Man, 45 years old)

OST clients expect accurate information from their pharmacist about the medication they receive and want to be treated with respect and understanding and as "normal" customers. They further expect pharmacists to trust them and to be flexible, e.g. when they do not have a drug prescription.

\section{The role of the prescribing doctor}

More than half of the respondents stated their doctor played a central role in their treatment process, not only as prescriber, but also as a person they can trust. The doctor's role goes beyond medical supervision and also their moral support and personal involvement is welcomed. It may not surprise that 35 respondents mentioned their doctor as the most important person to them in OST.

We almost never talk about methadone, unless my dose is no longer ok. If I have problems in whatever area of my life, we talk about that, how everything is going. That's really of fundamental importance to me. (Man, 40 years old)

About one third of the study participants said they just had a formal relationship with their doctor. According to them, it is not important to be monitored by the same doctor, since they only see them for medical check-ups and supervision. Clients' expectations regarding medical support, mainly refer to being treated in a respectful and individualised way. Large OST programs usually serve hundreds of clients without much differentiation, at the expense of individualised goal-setting and a personalised approach.

\section{Contacts with other OST staff}

A recurring theme regarding clients' contacts with all types of OST providers is the way they are approached by staff members. Respondents want to be seen as "normal people", rather than be regarded as "unreliable" or "weak" individuals. Several clients stated they are ashamed of asking help, 
because they are afraid their request will be rejected. Some participants have the feeling that (after years of OST) staff members do not longer believe in their recovery and are no longer willing to invest time in them. Alternatively, respondents suggested incorporating recovered drug users in OST staff, since they have experienced similar problems and can serve as role models. Also, OST clients prefer to talk about their current situation and future, rather than to keep on digging in the past and tell the same old story again.

It's always drug use, drug use, drug use they want to talk about. But let us for once not talk about my drug use. I would appreciate it if they would have attention for what went well in my life and not always everything bad. (Woman, 20 years old)

Another frequently cited issue was the lack of staff continuity, as respondents have often experienced significant staff turnover, which hampers the building of trusting relationships.

\section{Available and needed psychosocial support}

The quantitative assessments indicated that more than half of the respondents $(55.8 \%)$ received some form of psychosocial support in addition to OST during the three months preceding the interview. This support was most frequently provided by social workers $(51.2 \%)$, psychologists $(34.9 \%)$ or physicians working in specialised drug services (27.9\%). $28 \%$ of the respondents received weekly psychosocial support, while the frequency of these contacts was limited to once a month or less for $44 \%$ of the participants. The provision of psychosocial support appears to differ from program to program and some respondents stated they were not interested in receiving psychosocial support.

When talking about desired psychosocial support, respondents most frequently mentioned the need to be able to tell their story to someone with whom they feel connected to. Besides emotional support, respondents stressed the importance of practical support in OST, e.g. linking to ancillary services.

It should not be limited to listening, but sometimes they should do the effort to pick up the phone and to call to certain institutions, such as the social service department. [...] When I call myself, it's like I am talking to the walls. So that's important for me, that they sometimes not only listen, but are also willing to help. (Man, 61 years old)

Over one-third of the respondents expressed the need to have something to do, to deal with the emptiness of everyday life when they stop using (illicit) drugs.

As long as you have something to do, it is not a problem. [...]. It's a big difference when you wake up in the morning to go to your job. It has a large impact on my emotional well-being. What do I do now? I go and sit somewhere in the park with some people I know, drink a couple of beers and smoke a joint and make sure the day passes by. That's my daily life, but that's unbearable. (Man, 57 years old)

In addition, participants mentioned the need for a place where they could "hang around" and where they feel safe and can spend the day. Opening hours of specialised centres are often restricted to week days and to a few hours a day, urging for a place with flexible opening hours, adapted to their needs and offering opportunities for social contacts.

When we were in Brussels, we stayed the whole day at the centre. We could cook there and do all kind of activities. And here it is only picking up your methadone and off you go again, like a dog, back on the street. (Man, 45 years old)

During the interviews, clients stressed the importance of the voluntary and flexible character of psychosocial support. Participants expressed the desire to receive psychosocial support when they need it, not as part of an appointment system with strict time limits. Respondents' stories revealed that their lives are sometimes very unpredictable, urging for flexibility in the provision of psychosocial support. They prefer an individually assigned key worker they can address when needed, rather than (bi-)weekly talks or sessions with a dedicated worker.

In the beginning of my methadone treatment, I also had talks. And I had a lot of difficulties with those conversations. They always lasted for an hour and they kept droning on about the past. I couldn't stand it and after each session I went out to use drugs. (Man, 46 years old)

Finally, the need for outreach activities was suggested as home visits and meetings in clients' environment improve the accessibility of services and may provide important insights in persons' daily lives and in the things they are struggling with.

I think it would be very useful if they come to people's houses. Because people who are addicted are sometimes very isolated and they feel embarrassed to come outside and will not make it to the conversation room. (Woman, 38 years old)

\section{Discussion}

Based on this study of 77 opiate dependent individuals' experiences and expectations regarding OST and the provision of ancillary psychosocial support, it appears that the respondents were generally satisfied with these services. Still, despite abundant evidence that psychosocial support can enhance the effectiveness of OST (Amato et al., 2005; Vander Laenen et al., 2013; WHO, 2009), four in 10 clients did not receive psychosocial support during the three months preceding the interview. Yet, a substantial number of respondents (ranging from 49.2 to $19.4 \%$ ) stated they would have liked to receive psychosocial support in various areas (e.g. help at home, recreational activities). For most types of support (except group and individual psychotherapy), the 
number of participants wanting to receive psychosocial support outnumbered the number of respondents that actually received this support. Comparable observations emerged from an Australian study among OST clients, which showed that apart from pharmacological treatment - additional psychosocial support is often absent, despite clients' treatment needs on various life domains (Madden et al., 2008). Psychosocial support in addition to substitution treatment should be made more widely available and announced appropriately, in order that more service users can benefit from these services which are likely to affect their quality of life and overall treatment outcomes positively (De Maeyer, Vanderplasschen, \& Broekaert, 2010; Vander Laenen, 2013; WHO, 2009).

A recurring theme that emerged from the qualitative interviews is the importance of establishing trusting relationships with OST staff and being treated respectfully. The social stigma associated with drug use and OST in particular not infrequently results in disrespectful, humiliating contacts and may jeopardise individuals' sense of identity and recovery (Gilchrist et al., 2014; Harris \& McElrath, 2012). Besides nurses and other psychosocial workers, pharmacists and doctors play a central role in OST and can be seen as important sources of emotional support, especially for persons with few social contacts. Consequently, training and education programs and clinical guidelines for OST staff, including pharmacists and doctors, need to address issues of stigmatisation and the establishment of trusting relationships. Specific attention should be given to the very first service contacts, since clients often experience this contact as something stable that does not change a lot during the treatment process (Martin, Garske, \& Davis, 2000). Positive working alliances are characterised by the collaborative nature of the relationship, high involvement and interest of the key worker, an affective and equal relationship between client and key worker and shared decision-making about treatment goals. Positive, trusting relationships that are open to clients' subjective experiences are more likely to reinforce treatment retention and to affect overall treatment outcomes positively (Norcross \& Wampold, 2011).

Respondents frequently mentioned the need for a central key worker that they can address flexibly and as needed. Often, staff turnover and burocratic regulations (e.g. weekly appointments) hamper a flexible, individualised approach and continuity of care (Deering et al., 2011). Consequently, the establishment of safe and caring working environments is necessary to keep up workers' wellbeing and job satisfaction, as well as the creation of organisational structures that increase the availability of individual key workers or case managers who can address clients' needs appropriately over time (Dixon-Woods et al., 2005; Lilly, Quirk, Rhodes, \& Stimson, 2000; Vanderplasschen, Wolf, Rapp, \& Broekaert, 2007).

The needs for psychosocial support as expressed by the participants are diverse and illustrate the multiple problems that opiate users face throughout their treatment trajectory. Treatment needs change over time and several respondents emphasised the need for more differentiation in OST programs, as these now often focus on pharmacological treatment and primarily address marginalised heroin users, at the expense of the needs of stabilised and long-standing
OST clients. Differentiation may involve separate facilities for early and later stage OST clients, as the latter do not want to be confronted every day with drug use and dealing near the drug service. Also, many respondents stated they want to come off methadone eventually, but a recovery perspective is often missing in OST in Belgium, as in many other countries (Winstock et al., 2011). Liberal prescription policies do not stimulate opiate users to reduce their methadone use, although respondents say that they are tired of being dependent on methadone and of having no perspective in life.

OST clients do not want to be seen as passive recipients of care, but as "normal customers" and active agents of their recovery process (Harris \& McElrath, 2012). Attention needs to be paid to clients' voices throughout the treatment process and they should be involved in all decisions regarding substitute dosage and goal-setting. Research has demonstrated a clear gap between clients' and professionals' perceptions of the effectiveness of substitution treatment (Trujols et al., 2011). Consequently, goal setting should be based on a dialogical process to ensure that individual's goals and objectives correspond with the expectations and objectives of professional workers. Alternatively, the incorporation and monitoring of patient-reported outcomes such as quality of life and treatment satisfaction may contribute to more clientoriented services, based on individuals' needs and expectations (De Maeyer et al., 2011b; Trujols et al., 2011). Also, the provision of holistic, comprehensive services encompassing various life domains including psychosocial support is necessary to further improve the quality of OST and to promote opiate users' recovery and social inclusion (De Maeyer et al., 2011a; Vander Laenen, 2013; WHO, 2009).

\section{Study limitations}

The results of this study should be regarded in the perspective of some limitations. First, the sample size was not large $(N=77)$ given the large number of OST clients in Belgium and concerned a group of relatively old opiate users (mean age 41.6 years) who had been in substitution treatment for many years. Findings may therefore not be generalised to other groups of opiate users (e.g. those just starting treatment or no longer following OST) and to other countries. Still, participants' were recruited in various cities to get a comprehensive and in-depth understanding of OST provision in Belgium, until the point of data saturation. Second, the sample consisted exclusively of an urban population, disregarding aspects of OST in more rural areas. Third, most respondents were prescribed OST through a specialised drug service, so our findings may not be representative for individuals following OST in a private medical practice. Finally, the qualitative data-analysis may have been influenced by personal opinions while coding and structuring the data. We tried to minimise potential bias by appointing a second coder in cases where the coding of a text segment was unclear.

\section{Declaration of interest}

This manuscript is based on the study "Analysis and optimization of substitution treatment in Belgium", (SUBANOP), which has been commissioned by the Belgian 
Federal Science Policy (BELSPO) (DR/58). No conflicts of interest are reported by any of the authors.

\section{References}

Allen, C. (2007). Crime, drugs and social theory: A phenomenological approach. Devon, UK: Ashgate.

Amato L., Davoli, M., Perucci, C.A., Ferri, M., Faggiano, F., \& Mattick, R.P. (2005). An overview of systematic reviews of the effectiveness of opiate maintenance therapies: Available evidence to inform clinical practice and research. Journal of Substance Abuse Treatment, 28, 321-329.

Amato, L., Minozzi, S., Davoli, M., \& Vecchi, S. (2011). Psychosocial combined with agonist maintenance treatments versus agonist maintenance treatments alone for treatment of opioid dependence. Cochrane Database of Systematic Reviews, 10, CD005031.

Bacon, M., \& Seddon, T. (2013). The contractual governance of drug users in treatment. International Journal of Drug Policy, 24, 379-384.

Bao, Y., Liu, Z., Epstein, D.H., Du, C., Shi, J., \& Lu, L. (2009). A metaanalysis of retention in methadone maintenance by dose and dosing strategy. The American Journal of Drug and Alcohol Abuse, 35, 28-33.

Barnett, P.G., \& Hui, S.S. (2000). The cost-effectiveness of methadone maintenance. The Mount Sinai Journal of Medicine, 67, 365-374.

Brocato, J., \& Wagner, E.F. (2003). Harm reduction: A social work practice model and social justice agenda. Health \& Social Work, 28, 117-125.

Brun, C., \& Rapp, R.C. (2001). Strengths-based case management: Individuals' perspectives on strengths and the case manager relationship. Social Work, 46, 278-288.

Camfield, L., Crivello, G., \& Woodhead, M. (2009). Wellbeing research in developing countries: Reviewing the role of qualitative methods. Social Indicators Research, 90, 5-31.

Cowman, S. (1993). Triangulation - A means of reconciliation in nursing research. Journal of Advanced Nursing, 18, 788-792.

Deering, D.E.A., Sheridan, J., Sellman, J.D., Adamson, S.J. Pooley, S., Robertson, R., \& Henderson, C. (2011). Consumer and treatment provider perspectives on reducing barriers to opioid substitution treatment and improving treatment attractiveness. Addictive Behaviors, 36, 636-642.

Denning, P. (2001). Strategies for implementation of harm reduction in treatment settings. Journal of Psychoactive Drugs, 33, 23-26.

de los Cobos, J.P., Fidel, G., Escuder, G., Haro, G., Sánchez, N., Pascual, C., ... Trujols, J. (2004). A satisfaction survey of opioid dependent clients at methadone treatment centres in Spain. Drug and Alcohol Dependence, 73, 307-313.

de los Cobos, J.P., Valero, S., Haro, G., Fidel, G., Escuder, G., Trujols, J., \& Valderrama, J.C. (2002). Development and psychometric properties of the Verona service satisfaction scale for methadone-treated opioiddependent patients (VSSS-MT). Drug and Alcohol Dependence, 68, 209-214.

De Maeyer, J., Vanderplasschen, W., \& Broekaert, E. (2009). Exploratory study on drug users' perspectives on quality of life: More than health-related quality of life? Social Indicators Research, 90, 107-126.

De Maeyer, J., Vanderplasschen, W., \& Broekaert, E. (2010). Quality of life among opiate-dependent individuals: A review of the literature. International Journal of Drug Policy, 21, 364-380.

De Maeyer, J., Vanderplasschen, W., Camfield, L., Vanheule, S., Sabbe, B., \& Broekaert, E. (2011a). A good quality of life under the influence of methadone: A qualitative study among opiatedependent individuals. International Journal of Nursing Studies, 10, 1244-1257.

De Maeyer, J., Vanderplasschen, W., Lammertyn, J., van Nieuwenhuizen, C., Sabbe, B., \& Broekaert, E. (2011b). Current quality of life and its determinants among opiate-dependent individuals five years after starting methadone treatment. Quality of Life Research, 20, 139-150.

Dixon-Woods, M., Kirk, D., Agarwal, S., Annandale, E., Arthur, A., Harvey, J. ... Sutton, A. (2005). Vulnerable groups and access to health care: A critical interpretive review. London: National Coordinating centre for NHS Service Delivery and organization R\&D.
Drumm, R., Bride, D., Metsch, L., Page, J., Dickerson, K., \& Jones, B. (2003). "The rock always comes first": Drug users' accounts about using formal health care. Journal of Psychoactive Drugs, 35, 461-469.

Dunning, H., Williams, A., Abonyi, S., \& Crooks, V. (2008). A mixed method approach to quality of life research: A case study approach. Social Indicators Research, 85, 145-158.

European Commission. (2012). The EU Drugs Strategy (2013-2020). Official Journal of the European Union, 55, 1-26.

European Monitoring Centre for Drugs and Drug Addiction (EMCDDA). (2014). European Drug Report: Trends and developments 2014. Luxembourg: Publications Office of the European Union.

Fischer, B., Rehm, J., Kim, G., \& Kirst, M. (2005). Eyes wide shut? - A conceptual and empirical critique of methadone maintenance treatment. European Addiction Research, 11, 1-9.

Fischer, B., Rehm, J., \& Kim, G. (2001). Whose quality of life is it, really? British Medical Journal, 322, 1357-1360.

Fountain, J., \& Griffiths, P. (1999). Synthesis of qualitative research on drug use in the European Union: Report on an EMCDDA project. European Addiction Research, 5, 4-20.

Gilchrist, G., Moskalewicz, J., Nutt, R., Love, J., Germeni, E., Valkova, I., ... Baldacchino, A. (2014). Understanding access to drug and alcohol treatment services in Europe: A multi-country service users' perspective. Drugs: Education, Prevention \& Policy, 21, $120-130$.

Harris, J., \& McElrath, K. (2012). Methadone as social control: Institutionalized stigma and the prospect of recovery. Qualitative Health Research, 22, 810-824.

Hedrich, D., Pirona, A., \& Wiessing, L. (2008). From margin to mainstream: The evolution of harm reduction responses to problem drug use in Europe. Drugs-Education Prevention and Policy, 15, 503-517.

Kinlock, T. W., Gordon, M. S., Schwartz, R. P., Fitzgerald, T. T., \& O'Grady, K. E. (2009). A randomized clinical trial of methadone maintenance for prisoners: Results at 12 months postrelease. Journal of Substance Abuse Treatment, 37, 277-285.

Kolind, T. (2007). Form or content: The application of user perspectives in treatment research. Drugs: Education, Prevention \& Policy, 14, 261-275.

Kuckartz, U. (1998). WinMAX: Scientific text analysis for the social sciences, User's guide. Berlin: Udo Kuckartz, BSS.

Ledoux, Y. (2013). Characteristics of OST clients in Belgium: A secondary analysis of two Belgian databases. In Vander Laenen, F., Vanderplasschen, W., Smet, V., De Maeyer, J., Buckinx, M., Van Audenhove, S., ... Ansseau, M. (Eds.), Analysis and optimisation of substitution treatment in Belgium (SUBANOP) (pp. 87-104). Ghent: Academia Press.

Lilly, R., Quirk, A., Rhodes, G., \& Stimson, G.V. (2000). Sociality in methadone treatment: Understanding methadone treatment and service delivery as a social process. Drugs: Education, Prevention \& Policy, 7, 163-178.

Madden, A., Toby, L., Bath, N., \& Winstock, A.R. (2008). Satisfaction guaranteed? What clients on methadone and buprenorphine think about their treatment. Drug and Alcohol Review, 27, 671-678.

Martin, D.J., Garske, J.P., \& Davis, M.K. (2000). Relation of the therapeutic alliance with outcome and other variables: A metaanalytical review. Journal of Consulting and Clinical Psychology, 68, 438-450.

Moller, L., Karymbaeva, S., Subata, E., \& Kiaer, T. (2009). Evaluation of patients in opioid substitution therapy in the Kyrgyz Republic. Copenhagen: World Health Organization Regional Office for Europe.

Montagne, M. (2002). Appreciating the user's perspective: Listening to the "methadonians". Substance Use \& Misuse, 37, 565-570.

Neale, J., Allen, D., \& Coombes, L. (2005). Qualitative research methods within the addictions. Addiction, 100, 1584-1593.

Norcross, J.C., \& Wampold, B.E. (2011). Evidence-based therapy relationships: Research conclusions and clinical practices. Psychotherapy, 48, 98-102.

O'Gorman, A. \& Vander Laenen, F. (2010). Ethische aspecten van onderzoek. In T. Decorte \& D. Zaitch (Eds.), Kwalitatieve methoden en technieken in de criminologie (pp. 531-555). Leuven: Acco.

Ruefli, T., \& Rogers, S.J. (2004). How do drug users define their progress in harm reduction programs? Qualitative research to develop user-generated outcomes. Harm Reduction Journal, 1, 8. 
Stover, H. (2011). Barriers to opioid substitution treatment access, entry and retention: A survey of opioid users, patients in treatment, and treating and non-treating physicians. European Addiction Research, 17, 44-54.

Trujols, J., Sinol, N., Iraurgi, L., Batlle, F., Guàrdia, J., \& de los Cobos, J.P. (2011). Patient and clinician's ratings of improvement in methadone-maintained patients: Differing perspectives? Harm Reduction Journal, 8, 23.

Valderas, J.M., \& Alonso, J. (2008). Patient reported outcome measures: A model-based classification system for research and clinical practice. Quality of Life Research, 17, 1125-1135.

Vanagas, G., Padaiga, Z., \& Bagdonas, E. (2010). Cost-utility analysis of methadone maintenance treatment in Lithuania. Medicina (Kaunas), 46, 286-292.

Vanderplasschen, W., \& De Maeyer, J. (2007). The practice of case management for substance abusers: What's in a name? Adiktologie, 7, $460-469$.
Vanderplasschen, W., Wolf, J., Rapp, R. C., \& Broekaert, E. (2007). Effectiveness of different models of case management for substance-abuseing populations. Journal of Psychoactive Drugs, 39, $81-95$.

Vander Laenen, F., Vanderplasschen, W., Smet, V., De Maeyer, J., Buckinx, M., Van Audenhove, S., .. . De Ruyver, B. (2013). Analysis and optimisation of substitution treatment in Belgium (SUBANOP). Ghent: Academia Press.

Wiklund, I. (2004). Assessment of patient-reported outcomes in clinical trials: The example of health-related quality of life. Fundamental \& Clinical Pharmacology, 18, 351-363.

Winstock, A. R., Lintzeris, N., \& Lea, T. (2011). "Should I stay or should I go?', Coming off methadone and buprenorphine treatment. International Journal of Drug Policy, 22, 77-81.

World Health Organization (WHO). (2009). Guidelines for the psychosocially assisted pharmacological treatment of opioid dependence. Geneva: World Health Organization. 